\title{
2015 Whiteman Prize
}

UMBERTO BOTTAZZINI received the 2015 AMS Albert Leon Whiteman Memorial Prize at the 121st Annual Meeting of the AMS in San Antonio, Texas, in January 2015.

\section{Citation}

The 2015 Albert Leon Whiteman Prize of the American Mathematical Society is awarded to Umberto Bottazzini of the University of Milan for his many works in the history of mathematics, notably on the rise of modern mathematics in Italy and on analysis in the nineteenth and early twentieth centuries.

He is well known for his great attention to primary sources and has written on many aspects of the community of Italian mathematicians. Several early papers deal with Enrico Betti, the influence of Riemann on the Italian mathematicians, and the creation of the Scuola Normale Superiore di Pisa. These essays were collected in his book Va' pensiero: Immagini della matematica nell'Italia dell'Ottocento (Il Molino, Bologna, Italy, 1994), which is a substantial and important analysis that contributed to a much enhanced recognition of the role of Italian mathematicians from Betti and Cremona to Pincherle and Volterra. Then, with A. Conte and P. Gario, he coedited the CastelnuovoEnriques correspondence (Riposte Armonie: Lettere di Federigo Enriques a Guido Castelnuovo, Bollati, Boringhieri, Italy, 1996), and this lifelong interest in the mathematicians of Italy has recently led to his book (with Pietro Nastasi) La Patria ci Vuole Eroi: Matematici e Vita Politica Nell'Italia del Risorgimento (Zanichelli, Turin, Italy, 2013), which discusses the surprisingly extensive involvement of Italian mathematicians with politics in the decades before and after the unification of Italy.

His monograph The Higher Calculus: A History of Real and Complex Analysis from Euler to Weierstrass (English translation, Springer, New York, 1986) is the first book on the history of analysis to treat the real and complex aspects together, in keeping with their progress through the nineteenth century. It combines insights into the mathematics with a vigorous sensitivity to context and intellectual history, it embraces issues of foundational importance as they arose in applied mathematics, and it succinctly captures the lives and interests

DOI: http://dx.doi.org/10.1090/noti1232 of working mathematicians. The book marks the start of his important contributions to the history of complex function theory, the subject of his invited address to the International Congress of Mathematicians in Beijing in 2002. A full-length account (with Jeremy Gray) of the history of complex function theory from its beginnings to 1914 was published in 2013, entitled Hidden Harmony-Geometric

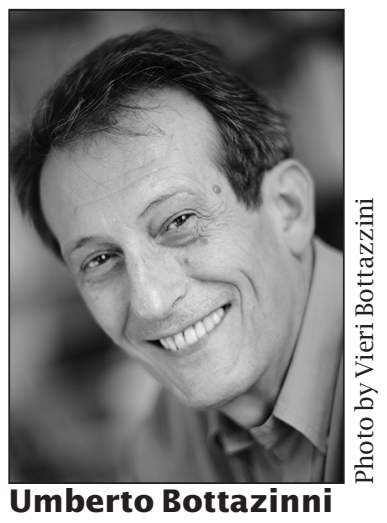
Fantasies: The Rise of Complex Function Theory (Springer, New York, 2013). The chapters on Cauchy and Weierstrass alone extend, deepen, and in many ways rewrite what has been claimed as the contributions of these two founding fathers of complex analysis.

Bottazzini is the author of Il Flauto di Hilbert (UTET, Torino, Italy, 2003), a stimulating history of mathematics from Newton and Leibniz to Hilbert's work and beyond, and of a profound 150-page analysis of Cauchy's Cours d'analyse (Editrice, Bologna, 1990) that is the definitive treatment. For many years he has maintained a weekly column on mathematical topics for the Italian newspaper Il Sole 24 Ore. The range and quality of his contributions are appreciated equally for their historical subtlety and mathematical insight, and this makes him a natural recipient of the Whiteman prize.

\section{Biographical Sketch}

Umberto Bottazzini studied mathematics at the University of Milan. After graduation in 1973 his interests soon turned toward the history of mathematics. He spent two years as assistant professor at the newly founded University of Calabria (Italy); then in 1979 he was appointed to the University of Bologna, where he taught for a decade before moving to the University of Palermo. In 1995 he was a resident fellow of the Dibner Institute for History of Science and Technology at the Massachusetts Institute of Technology, and he spent the years from 1996 to 1999 as a fellow of the interdisciplinary Research Center Beniamino Segre of the Academy of Lincei in Rome. Since 2004 he has been professor of the history of mathematics at the University of Milan. His research interests are devoted to the 
history of modern mathematics, and the history of complex analysis in particular. The latter was the subject of his invited address to the International Congress of Mathematicians (ICM) 2002 in Beijing. In addition he devoted a number of papers and books to the history of Italian mathematics in the nineteenth century. For more than twenty-five years he contributed the Sunday Supplement of the Italian newspaper Il Sole 24 Ore with a column on mathematical subjects, and for this activity in 2006 he was awarded the Pitagora Prize from the town of Crotone for the popularization of mathematics.

\section{Response from Umberto Bottazzini}

I feel deeply honored to receive the 2015 Albert Leon Whiteman Memorial Prize of the American Mathematical Society, especially so because as the fifth recipient I follow such esteemed colleagues as Thomas Hawkins, Harold Edwards, Jeremy Gray, and Joseph Dauben. I owe my deepest gratitude to the selection committee for this award, and to the American Mathematical Society for its support of the history of our discipline. In the early 1970s, when I became attracted by the history of mathematics and committed myself to an academic career in this area, the history of mathematics was poorly cultivated in Italy, and historical research work was hardly given any recognition by the professional mathematical society. Happily, things were to change quickly, and I benefited from the support and interest in my work provided by my colleagues in the mathematical departments where I happened to be appointed. At the same time, I had the chance to attend regularly the meetings on the history of mathematics held at the Mathematisches Institut Oberwolfach. There I became acquainted with many colleagues around the world, whose work has been an important source of inspiration to me. I also wish to thank my students, my coauthors and coeditors, and above all my wife and my son, who helped me much more than they may imagine.

\section{About the Prize}

The Whiteman Prize is awarded every three years to recognize notable exposition and exceptional scholarship in the history of mathematics. The prize was established in 1998 using funds donated by Mrs. Sally Whiteman, in memory of her husband, the late Albert Leon Whiteman. The prize carries a cash award of US\$5,000.

The Whiteman Prize is awarded by the AMS Council acting on the recommendation of a selection committee. For the 2015 prize, the members of the selection committee were Jeremy J. Gray, John McCleary, and Peter J. Olver.

Previous recipients of the Whiteman Prize are Thomas Hawkins (2001), Harold M. Edwards (2005), Jeremy J. Gray (2009), and Joseph W. Dauben (2012).

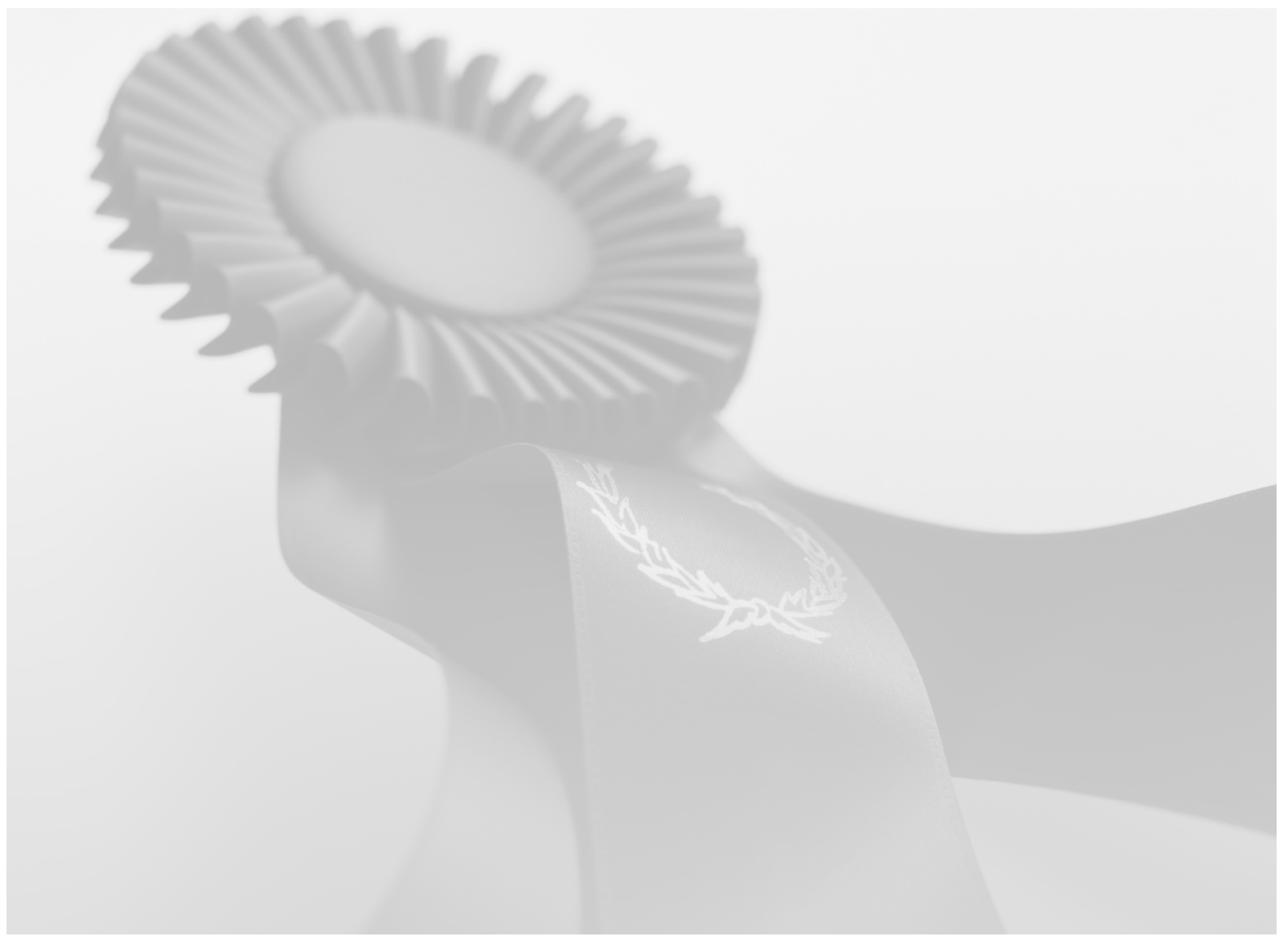

